\title{
PLURALISMO TERRITORIAL Y CONSTITUCIÓN
}

\author{
LUCIANO PAREJO ALFONSO \\ Catedrático de Derecho Administrativo \\ Universidad Carlos III de Madrid
}

SUMARIO

I. Introducción. II. Mirada sobre el presente cara al futuro: el Estado y su Constitución en el escenario supranacional e internacional III. Mirada retrospectiva y males o defectos a corregir o superar. IV. Estrambote sobre el interés general o público como clave para la revitalización del Estado.

\section{INTRODUCCIÓN}

Es mucho lo que se ha reflexionado y escrito ya, desde luego también desde la perspectiva jurídico-pública, sobre el desafío colectivo (en el sentido de situación difícil a la que es preciso enfrentarse) que representa el notable aumento en Cataluña del sentimiento independentista y, desde luego, la iniciativa de secesión emprendida utilizando las propias instituciones de autogobierno. Aunque el síntoma más agudo sea ahora el catalán, el malestar que padece la estructura estatal tiene mayor extensión, aunque esté ahora latente en el País Vasco ${ }^{1}$. No es infrecuente que las opiniones, que en estos últimos tiempos se han multiplicado, aborden las posibles soluciones y, situándolas en el terreno de la organización, se preocupen por derecho de proponer cambios más o menos concretos, vía reforma o, incluso, revisión constitucional.

1 Hoy parece relegada a cierto olvido la Propuesta del Parlamento Vasco para la Convivencia en Euskadi, Nuevo Estatuto Político de Euskadi (conocida como Plan Ibarretxe); iniciativa que, surgida asimismo de las instituciones de autogobierno, se debatió y rechazó en el Congreso de los Diputados hace apenas diez años. Estos días parece revivir, sin embargo, la cuestión vasca con la presentación en el Parlamento vasco, de un lado, por EH Bildu de una proposición de Ley de consulta, y, de otro lado, por UPyD de una proposición no de Ley dirigida a promover la ilegalización justamente de EH Bildu. 
La necesidad, más que la mera conveniencia, de actualizar nuestro orden constitucional parece fuera de toda duda. Y no menos evidente es que toda propuesta en tal sentido debería resultar de una reflexión del por qué y, sobre todo, del para qué, teniendo a la vista la situación presente (mirando desde luego al futuro), pero también (y partiendo de ella) de la experiencia histórica inmediata de puesta en pie y funcionamiento del Estado compuesto democrático y social de Derecho.

Los cambios en Europa y en el mundo determinantes de la situación presente son, en efecto, de enorme porte, incidiendo en el papel y la función de los Estados y, por tanto, también en el constitucionalismo: ni el Estado ni su Constitución son hoy lo que eran en 1978. Así lo acaba de poner de relieve, con gran eficacia, el recientemente fallecido maestro F. Rubio Llorente ${ }^{2}$. La tarea de actualización no puede cumplirse, pues, según las coordenadas de aquel momento constituyente y ha de tener lugar desde las que definen las transformaciones ya acontecidas y las que aún están en curso, toda vez que éstas prefiguran ya el mundo de hoy y el del futuro previsible.

Desde el punto de vista de las lecciones que deban seguirse de una mirada retrospectiva, los términos extremos alcanzados por el conflicto actual sobre la organización del Estado no autorizan a pensar en su apaciguamiento verdadero solo gracias a un pacto político sobre las cuestiones en torno a las que parecía inicialmente girar, sea la de las competencias, sea la de la financiación. Sin duda son múltiples las causas de la cuestión catalana y vasca (y en menor grado la gallega). Sin embargo, desde un punto de vista jurídico, que es el propio de estas líneas, parece inexcusable, como he adelantado, indagar en las que puedan derivar de la transición política a la democracia y la construcción del actual Estado de las autonomías. Pues la evidencia del balance abrumadoramente positivo de una y otro no debe impedir reconocer el fracaso, siquiera sea parcial, en el logro del objetivo perseguido con la decisión calificada en su día por F. Tomás y Valiente ${ }^{3}$ como «nervio y clave» de la Constitución: la adecuación de la organización del Estado a la secular estructura plural de España sobre la base de un específico equilibrio entre los principios de unidad y autonomía. Y ello, porque si la fórmula tenía sin duda el propósito de poner punto y final a los intentos de rectificación de una diversidad interna históricamente revelada como indomeñable, proporcionando el fluido preciso para disolver la tensión entre fuerzas integradoras y desintegradoras, lo cierto es que, primero la iniciativa del Parlamento vasco y ahora la del catalán vuelven a colocar el asunto en la casilla de salida.

2 F. Rubio Llorente, «Constitucionalismo contemporáneo y Constitución Europea», Revista de Libros, segunda época.

3 F. TOMÁS Y VALIENTE, «Raíces y paradojas de una conciencia colectiva», en A. RODRíGUEZ DE LAS Heras, V. Báez San José y P. Amador Carretero (edts.), Sobre la realidad de España, Universidad Carlos III de Madrid/Boletín Oficial del Estado, Madrid 1994, p. 26. 


\section{MIRADA SOBRE EL PRESENTE CARA AL FUTURO: EL ESTADO Y SU CONSTITUCIÓN EN EL ESCENARIO SUPRANACIONAL E INTERNACIONAL}

El Estado español miembro de la Unión Europea, aunque sigue reteniendo la soberanía última en tanto que uno de los «señores de los Tratados» (constitutivos de la Unión), no ejerce ya en plenitud dicha soberanía en la medida misma de la cesión de la parte de ésta necesaria para que la referida Unión pueda cumplir sus fines y objetivos. Y como ordenamiento jurídico está plenamente infraordenado, incluso en su norma superior o constitucional, a los Tratados en virtud de la declaración de éstos por el Tribunal de Justicia como instrumentos jurídicos que priman y, por tanto, prevalecen sobre aquél, incluida su lex superior. Y esto es así por la condición de comunidad de Derecho de la Unión y, por tanto, a pesar de todas las deficiencias que, desde el punto de vista del principio democrático, puedan achacarse a dicha Unión. Lo que quiere decir: unas normas (los Tratados) no emanados democrática y directamente de pueblo constituyente alguno pueden tener rango constitucional e imponerse (ciertamente de modo limitado, pues la Unión Europea es una estructura con poder circunscrito a un conjunto de fines y objetivos y, por tanto, con competencias de atribución) a la norma en que se expresa la voluntad soberana constituyente de los pueblos de los Estados miembros. Fácilmente se comprenden las consecuencias para la doble dimensión del Estado como poder y ordenamiento:

a) El status del Estado-poder ha dejado de ser definible por entero (con plena libertad) en sede constitucional por impedirlo la definición heterónoma de parte de dicho status (la correspondiente justamente a la condición de miembro de la Unión Europea), lo que incide notablemente, no solo en su actuación, sino ya en la regulación de su organización y funcionamiento internos. Y ello en la triple dirección ascendente (participación en las instituciones y demás organizaciones supranacionales y sus decisiones), horizontal (cooperación con los restantes Estados miembros) y descendente (colaboración, cooperación y, en su caso, coordinación en la aplicación de las políticas supranacionales; transposición y ejecución del Derecho comunitario derivado) y teniendo en cuenta que el principio de su autonomía organizativa y procedimental en el seno de la estructura supranacional tiene una potencia diversa y limitada en función de las necesidades de las políticas europeas frente a las decisiones de carácter organizativo y de actuación que estas últimas puedan imponer.

b) El sistema de fuentes del ordenamiento estatal en su conjunto tampoco es ya determinable por entero en sede constitucional clásica, toda vez que el ordenamiento supranacional europeo define sus propias fuentes y determina el rango y alcance (aplicabilidad directa o no) de cada una de ellas. De donde se sigue que el orden jurídico de los Estados miembros, incluso 
el de rango constitucional, está formado, en realidad, por un bloque normativo en cuyo seno a las normas emanadas de los poderes estatales se superponen (aunque sin llegar a cubrirlas por completo, al menos por ahora) normas comunitario-europeas.

Pero ese mismo Estado miembro de la Unión Europea es, además y simultánea e irremediablemente, miembro de una comunidad internacional cada vez más interdependiente basada, de un lado, en la organización mundial al servicio de la prevención de conflictos bélicos (la procura de la paz) y la promoción de los derechos inherentes a la dignidad de la persona (la ONU y su constelación de organizaciones), y, de otro lado, en la victoria del modelo de economía de mercado y, a lomos de la ciencia y la técnica, la progresiva mundialización de los diferentes mercados, generadoras, a su vez, de múltiples organismos encargados de la gestión de las diferentes dimensiones de tal fenómeno. En su conjunto estas estructuras internacionales producen decisiones condicionantes del margen de maniobra, prácticamente en todos los órdenes, de los Estados nacionales, desde la economía como es bien notorio, hasta el uso de la coacción inherente al poder no solo en sus relaciones recíprocas, sino también en el ámbito interno y en el reducto más íntimo de éste (como demuestra la doctrina de «la responsabilidad de proteger» ya formalmente sancionada —en 2005 — por la asamblea de la ONU y dirigida a legitimar la acción incluso militar de los Estados miembros - actuando en nombre de la comunidad internacional - para proteger los derechos esenciales de los ciudadanos conculcados gravemente por el propio Estado de pertenencia $)^{4}$.

Contemplada en el escenario que resulta de lo dicho, cualquier operación de actualización de nuestra Constitución ha de ser consecuente con las transformaciones sumariamente descritas y, manejando los conceptos «pueblo», «nación» y «soberanía» con su sentido y alcance jurídicos actuales, tener como referencia un Estado que, inserto en la comunidad internacional en calidad de miembro de la singular Unión Europea, sigue jugando en ella un papel decisivo desde el doble punto de la democracia y del progreso y efectividad de los derechos y deberes derivados de la dignidad de la persona en sociedad. Papel que hace de el bisagra entre la racionalidad propia del mundo transnacional e internacional, ajena a la lógica del constitucionalismo clásico, y la irrenunciable impuesta por la exigencia de la legitimación democrática del poder y la participación en su ejercicio, que remite sin duda a su construcción interna descentralizada para el aseguramiento de espacios sociales diversos de decisión sobre los asuntos de la vida colectiva.

4 El Real Instituto Elcano ha publicado, estando ya en prensa este texto y en su serie Documentos de Trabajo, el de E. MenéndeZ Del VAlle, Responsabilidad de proteger: la ONU en acción, en el que se realiza una excelente exposición de la doctrina aludida. El documento es accesible en: http://www.realinstitutoelcano. org/wps/portal/web/rielcano_es/contenido?WCM_GLOBAL_CONTEXT=/elcano/elcano_es/zonas_es/ dt2-2016-menendezdelvalle-responsabilidad-de-proteger-onu-en-accion 


\section{MIRADA RETROSPECTIVA Y MALES O DEFECTOS A CORREGIR O SUPERAR}

1. La sobrecarga definitoria de la Constitución y la pérdida progresiva, no obstante, de la conciencia nacional; cambios constitucionales que aconsejan

El acierto de la doble opción por la reforma política y la elaboración consensuada de la Constitución se produjo bajo el peso enorme de la herencia política de la dilatada dictadura franquista ${ }^{5}$. Si frente a ésta -y su interpretación parcial (nacional-católica) de la realidad histórica de España- la reacción lógica fue la consagración plena de la democracia y la descentralización político-administrativa del poder (en congruencia con el reconocimiento de la diversidad interna de la comunidad política constituida en Estado), lógico fue también, en lo que ahora más interesa, que frente a la patrimonialización ( «privatización por apropiación» la calificó F. Tomás y Valiente ${ }^{6}$ ) del nombre de España por el nacionalismo dominante, el consenso constituyente equilibrara el reconocimiento del derecho a la autonomía de las regiones y nacionalidades con la afirmación enfática de la soberanía «nacional» (art. 1.2) y la fundamentación de la Constitución en la «indisoluble unidad de la nación española, patria común e indivisible de todos los españoles» (art. 2).

En estas fórmulas se incluyen unas apelaciones a la nación y las nacionalidades y, sobre todo, un emparejamiento de nación y Estado y, en su caso, Comunidad Autónoma y «nacionalidad» que, si acertadas al tiempo de su consagración y eficaces en su finalidad (como demuestra el mismo desarrollo espectacular del Estado autonómico) pueden hoy verse, sin perjuicio de la persistencia de su virtualidad y con mayor frialdad, como no estrictamente indispensables por ser difícil su asidero en el terreno jurídico (en tanto pertenecientes más bien al orden de los sentimientos $)^{7}$. Hay aquí, en efecto, una cierta sobrecarga definitoria que luego, sin pretenderlo, ha comportado dificultades constitucionales de enorme porte, con incidencia indudable e innecesaria (desde el punto de vista estrictamente jurídico-constitucional) en la cuestión que nos ocupa. Baste recordar el debate suscitado por la utilización en el Estatuto de Autonomía de Cataluña de 2006 de «pueblo

5 Puede releerse hoy a este respecto, por ilustrativo, el texto dedicado por G. Peces-Barba MartíNEZ, uno de los «padres» del proyecto de Constitución, al consenso y la filosofía política del Estado de las autonomías en su intervención en el seminario sobre la realidad de España celebrado en la Universidad Carlos III de Madrid en 1992 (bajo el expresivo título «La idea de España en el Estado de las Autonomías», en la obra colectiva citada en nota anterior, pp. 145 a 150).

6 F. Tomás y VAliente, op. cit, p. 20.

7 Están ausentes en el decisivo precedente de la Constitución de 1931. Su artículo 1 realizaba solo la siguiente doble afirmación: «España es una República democrática....» (en la que «los poderes de todos los órganos emanan del pueblo») y «la República constituye un Estado integral, compatible con la autonomía de los Municipios y las Regiones» (la apelación a la soberanía solo aparecía en la fórmula de promulgación).

UNED. Teoría y Realidad Constitucional, núm. 37, 2016, pp. 249-271 
de Cataluña», «nación» $\mathrm{y}$ «símbolos nacionales», los términos de su resolución en la STC 31/2010, de 28 de junio ${ }^{8}$ y sus efectos en la sociedad catalana.

No es que en nuestro entorno más inmediato las Constituciones no contengan en absoluto proclamaciones parecidas. Pero en unos casos son menos problemáticas (por tratarse de Estados-nación fuertemente unitarios, como Francia) y

8 No está de más recordar lo dicho por el TC en los fundamentos jurídicos a propósito de los términos aludidos en el texto:

— En el fundamento 9 se señala, a propósito de la expresión «pueblo de Cataluña», que: «El pueblo de Cataluña no es, por tanto, en el artículo 2.4 EAC, sujeto jurídico que entre en competencia con el titular de la soberanía nacional cuyo ejercicio ha permitido la instauración de la Constitución de la que trae causa el Estatuto que ha de regir como norma institucional básica de la Comunidad Autónoma de Cataluña. El pueblo de Cataluña comprende así el conjunto de los ciudadanos españoles que han de ser destinatarios de las normas, disposiciones y actos en que se traduzca el ejercicio del poder público constituido en Generalitat de Cataluña. .... Tal es el designio que justifica la expresión «pueblo de Cataluña» en el artículo 2.4 EAC, por entero distinta, conceptualmente, de la que se significa en nuestro Ordenamiento con la expresión «pueblo español», único titular de la soberanía nacional que está en el origen de la Constitución y de cuantas normas derivan de ella su validez».

- Y en el fundamento 12 a propósito de «símbolos nacionales» y «nación», que: «Es preciso convenir ... en que el término «nación» es extraordinariamente proteico en razón de los muy distintos contextos en los que acostumbra a desenvolverse como una categoría conceptual perfectamente acabada y definida, dotada en cada uno de ellos de un significado propio e intransferible. De la nación puede, en efecto, hablarse como una realidad cultural, histórica, lingüística, sociológica y hasta religiosa. Pero la nación que aquí importa es única y exclusivamente la nación en sentido jurídico-constitucional. Y en ese específico sentido la Constitución no conoce otra que la Nación española, con cuya mención arranca su preámbulo, en la que la Constitución se fundamenta (art. 2 CE) y con la que se cualifica expresamente la soberanía que, ejercida por el pueblo español como su único titular reconocido (art. 1.2), se ha manifestado como voluntad constituyente en los preceptos positivos de la Constitución Española.

En el contexto del Estado democrático instaurado por la Constitución, es obvio que, Cabe ... la defensa de concepciones ideológicas que, basadas en un determinado entendimiento de la realidad social, cultural y política, pretendan para una determinada colectividad la condición de comunidad nacional, incluso como principio desde el que procurar la conformación de una voluntad constitucionalmente legitimada para, mediando la oportuna e inexcusable reforma de la Constitución, traducir ese entendimiento en una realidad jurídica. En tanto, sin embargo, ello no ocurra, las normas del Ordenamiento no pueden desconocer ni inducir al equívoco en punto a la «indisoluble unidad de la Nación española» proclamada en el artículo $2 \mathrm{CE}$, pues en ningún caso pueden reclamar para sí otra legitimidad que la que resulta de la Constitución proclamada por la voluntad de esa Nación, ni pueden tampoco, al amparo de una polisemia por completo irrelevante en el contexto jurídico-constitucional que para este Tribunal es el único que debe atender, referir el término «nación» a otro sujeto que no sea el pueblo titular de la soberanía.

La referencia del artículo 8 EAC a los símbolos nacionales de Cataluña podría inducir a esa indebida confusión si pretendieran extraerse de la mención del preámbulo a determinada declaración del Parlamento de Cataluña sobre la nación catalana unas consecuencias jurídico constitucionales contradictorias con el sentido preciso del artículo 2 CE en punto a la sola y exclusiva relevancia constitucional de la Nación española. Sin embargo, cabe interpretar, de acuerdo con la Constitución, que con la calificación como «nacionales» de los símbolos de Cataluña se predica únicamente su condición de símbolos de una nacionalidad constituida como Comunidad Autónoma en ejercicio del derecho que reconoce y garantiza el artículo 2 CE, pues así expresamente se proclama en el artículo 1 EAC y se reitera en el artículo 8 EAC. Se trata, en suma, de los símbolos propios de una nacionalidad, sin pretensión, por ello, de competencia o contradicción con los símbolos de la Nación española» 
en todos son más sobrias9. Es, en todo caso, la Ley Fundamental de Bonn, de indudable influencia en nuestro constitucionalismo, la que se pronuncia de forma más escueta, en la línea, por demás, de nuestra Constitución de 1931: al establecer, en su artículo 20, los fundamentos del orden constitucional sencillamente dice que «la República Federal de Alemania es un Estado federal democrático y social» en la que «todo poder del Estado emana del pueblo», el cual es ejercido por éste «mediante elecciones y votaciones y por intermedio de órganos especiales de los poderes legislativo, ejecutivo y judicial».

Decisivo es, no obstante, que — como también ya dejó señalado F. Tomás y Valiente ${ }^{10}$ — la apuntada abundancia definitoria no solo no ha servido, además y en cualquier caso, para contrarrestar el abuso del nombre de España en la dictadura franquista, sino que tampoco ha podido impedir, ya en el período democrático, el desuso de dicho nombre, cuando no la negación de la realidad del todo nacional, como efecto del rechazo al nacionalismo dominante en la dictadura (procurándose evitar el empleo de los términos «nación»o «nacional» mediante el recurso a circunloquios o términos en modo alguno equivalentes, tales como país y, sobre todo, «Estado español»). No cabe en todo caso desconocer el desarrollo, en el período democrático, de un doble y paralelo proceso: debilitación, con carácter general, de la conciencia nacional del todo (o referida a la realidad España constituida por una historia, una lengua y una cultura comunes) y fortalecimiento tanto de la conciencia nacional de partes (o referida, como mínimo, a las realidades País Vasco y Cataluña y, en menor medida, Galicia), como del particularismo regional ${ }^{11}$. Lo que, en el proceso de construcción y consolidación del Estado autonómico, ha tenido una clara proyección en la afirmación de la lógica de la estructura estatal y de su nítida percepción ciudadana; una proyección, favorecida por el propio texto constitucional ${ }^{12}$, consistente en su desdibujamien-

9 Ninguna de las Constituciones de los países colindantes o más cercanos (Francia, Portugal e Italia) define el país correspondiente como nación. Se limitan a afirmar —en sus respectivos primeros artículosque Francia, Portugal e Italia son Repúblicas. Eso si, o bien afirman que la República es indivisible, además de laica, democrática y social (la francesa, que luego en sus artículos 2 y 3 emplea el calificativo «nacional» al tratar de la bandera y el himno y al afirmar la residencia de la soberanía en el pueblo) o bien la califican de democrática en la que la soberanía pertenece al pueblo, siendo una e indivisible y reconociendo y promoviendo las autonomías locales (arts. 1 y 5 de la italiana) o, después de calificarla de soberana, señalan que es un Estado democrático, basado en la soberanía popular, que — esta sí- es una e indivisible y reside en el pueblo (arts. 1, 2 y 3 de la portuguesa).

10 F. Tomás y Valiente, op. cit, en nota 2, p. 21.

11 P. LAín Entralgo dejó dicho en 1992, en su contribución al seminario sobre la realidad de España celebrado en la Universidad Carlos III de Madrid, que: «Hace unos meses escribí que si a los españoles actuales les preguntasen “¿Es usted español? ¿Se siente usted español?”, la respuesta “Ni soy español, aunque mi partida de nacimiento lo diga, ni me siento español” sería en Cataluña y Euskadi, menos en Galicia, inquietantemente repetida. Así lo sigo pensando» (Una y diversa España, en la obra colectiva citada en nota 2, p. 236).

12 Ya en su Sentencia 32/1981 señaló el Tribunal Constitucional que:

«Es obvio, para comenzar, que el término Estado es objeto en el texto constitucional de una utilización claramente anfibológica. En ocasiones (así, arts. 1, 56, 137 y en la propia rúbrica de su Título VIII, por mencionar sólo 
to y hasta dilución manifestada, por de pronto, en la necesidad de precisar el uso de los términos (Estado en sentido estricto o, por el contrario, global o como un todo) o lo obvio (que las Comunidades Autónomas, por ejemplo, son también Estado) o en la dificultad para llamar por su nombre al Gobierno nacional o español (recurso, por ejemplo, a la expresión Gobierno del Estado) en contraste con la ausencia de dicha dificultad en el caso de los Gobiernos autonómicos (Gobierno vasco o de Euskadi; Gobierno catalán o de Cataluña, por ejemplo) o la necesidad del recurso a circunloquios (p. ej. instituciones generales).

Factor decisivo en la pérdida de pulso de la expresada conciencia nacional española (compatible, en todo caso, con la de ser vasco, catalán o gallego) ha sido la progresiva pérdida de energía y, por tanto, de vis atractiva y, por ello, integradora, del proyecto de vida en común representado por el orden de derechos fundamentales y libertades públicas y principios rectores de la política social y económica ${ }^{13}$. El potente impulso inicial suministrado a tal proyecto por el Tribunal Constitucional en la primera mitad de su existencia se ha ido consumiendo hasta prácticamente desaparecer de la labor del intérprete supremo de la Constitución (cada vez menos «fuente» de expresión de las decisiones basales y guía de la convivencia) y garante último de la tutela judicial efectiva (cada vez más parapetado en la subsidiariedad de su función de amparo crecientemente distanciado de la verdadera tutela mediante construcciones jurídicas progresivamente alambicadas y generadoras de obstáculos procesales). Sea como fuere, lo cierto es que la doctrina del Tribunal Constitucional ha dejado de ser faro en la navegación accidentada que supone la continua recreación de las condiciones de vida en común y de la unidad sustantiva o material constitucional en el funcionamiento del conjunto de poderes constituidos «repartidos» territorialmente en un Estado incorporado, estando aún en reconstrucción, al proyecto de integración europea. No hay en ella, en cualquier

algunos ejemplos) el término Estado designa la totalidad de la organización jurídico-política de la nación española, incluyendo las organizaciones propias de las nacionalidades y regiones que la integran y la de otros entes territoriales dotados de un grado inferior de autonomía; en otras, por el contrario (así, en los arts. 3.1, 149, 150), por Estado se entiende sólo el conjunto de las instituciones generales o centrales y sus órganos periféricos, contraponiendo estas instituciones a las propias de las Comunidades Autónomas y otros, entes territoriales autónomos. Esta contraposición, que puede originar algún equívoco, no puede hacer olvidar, sin embargo, que la Constitución es la norma suprema del Estado como totalidad y que, en consecuencia, sus principios obligan por igual a todas las organizaciones que forman parte de esa totalidad...»

Sobre ello ha vuelto luego, como, por ejemplo, en la STC 119/1992, de 18 de septiembre.

13 Aquí se revela lo avanzado de la CE de 1978, si se la entiende — como debe ser- definitoria de su orden dogmático (los derechos y las libertades nucleados en torno a la dignidad de la persona en sociedad y, por tanto, los principios rectores de la política social y económica al servicio de tal dimensión social) como verdadero proyecto de vida en el todo nacional. Lo que quiere decir: un proyecto expresivo de la luego calificada por el Tribunal Federal Constitucional alemán (como inmediatamente se precisará) como «identidad constitucional» desde el que el Estado se ofrece en su papel más genuino en el mundo actual descrito en el apartado II. Véase, respecto al aludido significado para la Constitución y su Estado, L. PArejo Alfonso, «España, Estado español y Constitución», en la obra colectiva ya citada Sobre la realidad de España, especialmente las líneas dedicadas a la determinación jurídica de la identidad de la nación y del Estado españoles (pp. 181 a 186) 
caso, nada parecido a la ciertamente controvertida y sin duda discutible desde otros puntos de vista, pero reveladora de una plena conciencia de la función institucional propia, doctrina del Tribunal Constitucional Federal alemán sobre la «identidad constitucional» (considerada esencial e inviolable), que se nutre sustancialmente del orden de derechos fundamentales en democracia ${ }^{14}$.

La legislación y, por tanto, las políticas públicas — formuladas y ejecutadas, una y otras, en términos que están lejos de evidenciar progreso sustantivo en los requerimientos que les impone la democracia — han podido ir desarrollándose sin claros referentes constitucionales, bajo la influencia de los de distinto rango comunitario-europeos y expuesta por completo a las exigencias de cada momento y materia (tanto en las épocas de aparente abundancia, como en las de apuro y restricciones), pero progresivamente impregnadas del predominio de los requerimientos de la economía sobre los valores sustantivos de la dignidad de la persona y de la cohesión social (subyacente a los principios rectores de la política social y económica). Este último predominio luce especialmente en la modulación del Estado prestacional —en algunos sectores no precisamente secundarios de la economía - en términos de mero garante de las prestaciones y la neutralización política de dichos sectores mediante su autonomía gestionada por Autoridades Independientes. No es sorprendente que en los últimos tiempos en que la crisis económica aún no superada ha agudizado dicho fenómeno, a la ciudadanía le sea imposible percibir que la acción del poder público —aún dentro de las dificultades y limitaciones- permanece fiel al proyecto de convivencia expresado en el texto constitucional, sobre todo en punto a garantía de la promoción de la integración social vía igualdad plena y efectiva en las condiciones básicas de vida.

Poco se puede hacer en sede de reforma constitucional, sin embargo, para superar estos males de la España de hoy, pues éstos reclaman más bien una regeneración o, si se prefiere, revitalización de la política y la sociedad. El Derecho, la norma — por más que sea constitucional- carece de tal efecto taumatúrgico. Pero sí está en su mano no dificultar y propiciar los procesos correspondientes. Siendo así que, por razón de los males detectados que deben afrontarse, parece inevitable la introducción de cambios en el texto constitucional, sería aconsejable:

1. De acometerse una ciertamente delicada revisión (en su caso parcial) y solo en tal caso: una redefinición constitucional más contenida y sobria de España, que se atuviera a su constitución en un Estado democrático y social de Derecho, evitando toda referencia en este punto a la estructura territorial del mismo. En rigor no haría falta nada más, puesto que las alusiones a la nación y las nacionalidades pueden ser desde luego suscep-

14 BVerfGE 37, 271; 73, 339; 89, 155 y, más recientemente, 2BvE 2/08 y 5/08, 2 BvR 1022 y 1259/08 y 182/09, de 30 de junio de 2009 a propósito del Tratado de Lisboa.

UNED. Teoría y Realidad Constitucional, núm. 37, 2016, pp. 249-271 
tibles de una interpretación más flexible que la efectuada en la STC $31 / 2010$, de 18 de junio ${ }^{15}$.

Tal modo de proceder perseguiría concentrar todo lo relativo a la organización territorial del Estado en su sede propia (el título VIII) y permitir el tratamiento en ella de las instancias territoriales (hoy Comunidades Autónomas) como entidades políticas de carácter estatal (en cuanto partes del mismo) que institucionalizan las correspondientes comunidades políticas según sus específicas características. Y ello desde la idea de que al igual que ha sido y es posible la cesión de soberanía hacia «arriba» (Unión Europea), tanto más es plausible el reparto interno - hacia «abajo» y a título de constituida- de la soberanía ejercida por el pueblo español en el acto constituyente. En los términos lacónicos, pero efectivos, de la Ley Fundamental de Bonn: desde la idea de que todo poder constituido emana del pueblo y sin necesidad de mayores precisiones definitorias de las entidades políticas territoriales, incluida la general.

2. Sí parece inexcusable en cualquier caso un replanteamiento del papel y la función esenciales, respecto del todo, de las instituciones generales, que naturalmente habría de repercutir en sus competencias. La finalidad a conseguir sería:

a) Por una parte, destacar — como fundamentales y transversales - las tareas relativas a la garantía de:

i) La igualdad de todos los ciudadanos en punto al ejercicio de los derechos fundamentales y las libertades públicas y el cumplimiento de los deberes constitucionales; en particular —en el contexto de la concreción de los principios de la política económica y social - desde el punto de vista de la equivalencia de las condiciones de vida en todo el territorio del Estado (en el sentido - como en el constitucionalismo alemán - de un mínimo de calidad de vida y cohesión social).

Pero en el entendido de que esta tarea no tendría el tratamiento de un título competencial ordinario, por inscribirse - con sentido de acotación y contención de la intervención de la instancia generalmás bien en la relación de dicha instancia y las territoriales de acuerdo con la distribución de competencias entre ellas.

ii) El mantenimiento de la unidad jurídica y económica fundamentales.

15 Como prueba la nada sospechosa opinión de quien fuera uno de los padres del proyecto de Constitución, G. Peces-Barba Martínez, quien en 1992 dejó escrito que «Con estos antecedentes, y con el rechazo de los nacionalismos excluyentes, la Constitución se asienta sobre la idea de España como nación de naciones y regiones»» (op. cit, p. 148). 
b) Y, por otra parte, asegurar la habilitación del Estado para desarrollar - en todo caso en concurrencia con las entidades políticas territoriales - una política educativa y cultural trasunto, exclusivamente, de la realidad común de España como historia, lengua y cultura comunes.

\section{La sobrecarga de la reconstrucción y el funcionamiento del Estado constitucional; sus consecuencias y los cambios que demandan}

Los resultados sobresalientes obtenidos por la solución constitucional no pueden ocultar las consecuencias negativas que para la consolidación del Estado de las autonomías ha tenido el hecho decisivo de su desarrollo como proceso lo suficientemente abierto como para que aún hoy pueda considerarse no concluida (no cerrada) la (re)construcción de tal novedoso Estado. Con ello no se pretende tanto la formulación de un juicio crítico (que sería cuando menos anacrónico por desconocedor de las circunstancias difíciles del proceso), cuanto la constatación objetiva de un resultado, derivado de una doble causa:

a) Una calificable de originaria, identificable con la anticipación de las llamadas preautonomías y la victoria, desde el primer día del período constitucional, de la idea de la «desconstitucionalización» del modelo territorial (recuérdense las alusiones a la autonomía a la carta y el énfasis en el llamado principio dispositivo) frente a la de deducibilidad del texto fundamental cuando menos de unas directrices y criterios claros de organización territorial del Estado. Pues si la primera condicionó el modelo preparando la generalización de las autonomías políticas, la segunda —la supuesta desconstitucionalización de dicho modelo- anulaba la idea (inscrita para algunos en el consenso constitucional) de existencia de un pacto sobre aquella organización y portaba en sí, por ello, el germen del desacuerdo con el curso del proceso (en la medida en que se apartara de lo que se entendía pactado o consensuado) y, por tanto, el desapego respecto del concreto modelo en que tal proceso se iba concretando (lo que, en términos constitucionales, podía significar, y ha significado finalmente, pérdida de vigor en la lealtad a la Constitución) ${ }^{16}$.

b) La segunda causa, inmediatamente sobrevenida (apenas siete años después de la promulgación del texto fundamental), derivó de la incorporación a las entonces Comunidades Europeas y hoy Unión Europea, en tanto que - aparte el impacto de suyo de aquella incorporación sobre la lógica de organización y funcionamiento del Estado, aún en decanta- 
ción- supuso el incremento de la complejidad del proceso autonómico por injerto en él del también proceso hacia una integración supranacional solo definible haciendo camino con el báculo del llamado método comunitario.

El resultado fue el padecimiento por el proceso autonómico de un síndrome de indigestión, que se entiende bien si se tiene en cuenta —además de las vicisitudes que hubieron de ser afrontadas también tempranamente (en especial las crisis económicas de finales de los años setenta y primera mitad de los ochenta y de la también primera mitad de los años noventa del S. xx)— la inevitable impresión de vaciamiento del viejo odre central (sin su relleno de vino nuevo) por efecto de la cesión de soberanía constituida tanto hacia «arriba» (la actual UE), como, especialmente, hacia «abajo» (las Comunidades Autónomas) ${ }^{17}$. Síndrome que, sobre hacer impracticable la solución serena y tempestiva de todas las cuestiones planteadas por el proceso y su avance de forma armónica y sólida (sobre la base de sus verdaderos fundamentos constitucionales), impuso una sustancial continuidad por debajo de las innovaciones que se iban introduciendo- en la lógica de funcionamiento del Estado, solo que expresada ahora en la doble instancia territorial de su estructura (cada una de ellas ejerciendo, por separado y con ánimo expansivo, las propias competencias —entendidas como habilitantes para la definición, sin más y por separado, del interés público o general objetivo en la materia y la resolución de las discrepancias vía conflicto y, en su caso, negociación política). Esta situación, que está también sin duda en el origen de la incomodidad actual con la estructura territorial del Estado, ha estado favorecida tanto por la singularidad y complejidad del sistema de distribución interna territorial del poder (especialmente por razón del criterio distributivo basado en el par «bases»/»coordinación» — «desarrollo» ${ }^{18}$ ), como por la prudencia mal entendida del Tribunal Constitucional a la hora tanto de atajar los excesos en el uso de los títulos competenciales (principalmente en punto a lo básico en la legislación ordinaria y las circunstancias habilitantes para la utilización del Decreto-Ley y los límites objetivos de este instrumento), como — más allá de meras apelaciones genéricas— de precisar la incidencia en el ejercicio de las competencias de los principios de colaboración, cooperación y coordinación ${ }^{19}$. Se comprende, así, la facilidad, en general, pero sobre todo

17 Baste con recordar el muy temprano y fracasado episodio de «armonización» del proceso autonómico basado en la afirmación de la existencia de una situación de heterogeneidad precisada de dicha armonización.

18 Extremo en el que es existe abundante literatura y suficiente consenso, que hace de todo punto innecesario abundar en el.

19 Sobre una solución posible a la necesaria interacción de los distintos niveles de gobierno en el Estado Autonómico y su posible solución: L. Parejo Alfonso, «El Gobierno de la Nación y los Gobiernos de las Autonomías territoriales; un problema de articulación», DA 215, julio-septiembre de 1988; y sobre la colaboración, cooperación y coordinación como elementos determinantes en el ejercicio de las competencias, L. PARejo Alfonso, «Notas para una construcción dogmática de las relaciones interadministrativas», RAP 174, septiembre/diciembre 2007, pp. 161 a 191. 
en la situación de crisis sistémica desencadenada en 2007/08 y persistente hoy, del recurso más que abundante al Decreto-Ley con alcance a veces ciertamente discutible y el dictado de Leyes que prescinden de la lógica impuesta por la estructura estatal e, incluso, persiguen un efecto recentralizador al amparo de los requerimientos económico-financieros derivados de la pertenencia a la UE.

Esta experiencia es rica en enseñanzas a tener en cuenta en posibles cambios en la Constitución, cuya traducción en propuestas concretas ha de ser fruto del pertinente acuerdo político ${ }^{20}$. No es impertinente señalar, sin embargo, la procedencia de:

a) Partir de la doble condición del Estado como parte (miembro) de un todo supranacional (la Unión Europea) y un todo nacional compuesto de entidades políticas territoriales específicas y diversas entre sí en un contexto internacional cada vez más interpenetrado y denso y, por ello, capaz de condicionar e incidir en las políticas europeas e internas, regulando directamente — dada la peculiar economía del espacio decisional y de actuación supranacional europeo (en cuanto articulado sobre fines y objetivos prevalentes respecto de los títulos competenciales)_ las consecuencias internas de su estatuto de miembro, no sólo en los aspectos más estáticos (aceptación de la cesión de soberanía a las instituciones europeas vía tratados y obligaciones derivadas de la pertenencia la Unión y la responsabilidad por incumplimiento; todo ello, en relación al entero Estado), sino también en los dinámicos de funcionamiento, en la línea (adaptándola obviamente a nuestra organización territorial) de los artículos 88-4 a 88-7 de la Constitución francesa ${ }^{21}$ o, mejor aún (por tratarse de un Estado de estructura fe-

20 Es obvio que el defectuoso tratamiento de las Haciendas públicas propias de un Estado de las características del autonómico ha sido también una grave deficiencia del proceso autonómico precisada igualmente de superación. Aquí, sin embargo, se prescinde de hacer propuestas en este orden, que escapa a la competencia del autor.

21 Estos preceptos rezan así: Artículo 88-4: «El Gobierno someterá a la Asamblea Nacional y al Senado, en el momento de su traslado al Consejo de la Unión Europea, los proyectos o propuestas de actos de las Comunidades Europeas y de la Unión Europea. Según las modalidades fijadas por el reglamento de cada Cámara, podrán adoptarse resoluciones europeas, llegado el caso fuera de los períodos de sesiones, sobre los proyectos o las propuestas mencionados en el primer párrafo, así como sobre cualquier documento que emane de una institución de la Unión Europea. En cada Cámara parlamentaria se instituirá una comisión encargada de los asuntos europeos». Artículo 88-5: «Todo proyecto de ley que autorice la ratificación de un tratado relativo a la adhesión de un Estado a la Unión Europea será sometido a referéndum por el Presidente de la República. Sin embargo, mediante el voto de una moción adoptada en términos idénticos por cada Cámara por mayoría de las tres quintas partes, el Parlamento podrá autorizar la adopción del proyecto de ley según el procedimiento previsto en el tercer párrafo del artículo 89». Artículo 88-6: «La Asamblea Nacional o el Senado podrán emitir dictamen razonado sobre la conformidad de un proyecto de acto legislativo europeo con el principio de subsidiariedad. Dicho dictamen, del que se dará cuenta al Gobierno, será remitido por el Presidente de la Cámara correspondiente a los Presidentes del Parlamento Europeo, del Consejo y de la Comisión Europea. Cada Cámara podrá interponer un recurso ante el Tribunal de Justicia de la Unión Europea contra un acto legislativo europeo por violación del principio de subsidiariedad. El recurso será trasladado por 
deral), del artículo 23 de la Ley Fundamental de Bonn ${ }^{22}$ (tanto más, cuanto que tal precepto aparece ubicado sistemáticamente en el título referido a la organización del Estado, el II relativo a «La Federación y los Länder» $)^{23}$. Y, por supuesto, abordando también con mayor detenimiento su posición y acción en el plano de las relaciones internacionales.

el Gobierno al Tribunal de Justicia de la Unión Europea. A estos fines se podrán aprobar resoluciones, incluso fuera de los períodos de sesiones, según modalidades de iniciativa y discusión fijadas por el reglamento de cada Cámara. A petición de sesenta diputados o sesenta senadores, el recurso será de derecho». Artículo 88-7: «Mediante moción votada en términos idénticos por la Asamblea Nacional y el Senado, podrá el Parlamento oponerse a la modificación de las normas de aprobación de actos de la Unión Europea en los casos previstos, en materia de revisión simplificada de los tratados o de cooperación judicial civil, por el Tratado de la Unión Europea y el Tratado de Funcionamiento, modificados por el Tratado de Lisboa de 13 de diciembre de 2007».

22 El citado artículo 23 [Unión Europea - protección de los derechos fundamentales — principio de subsidiariedad] dice:

«(1) Para la realización de una Europa unida, la República Federal de Alemania contribuirá al desarrollo de la Unión Europea, que está obligada a la salvaguardia de los principios democrático, del Estado de Derecho, social y federativo y del principio de subsidiaridad y garantiza una protección de los derechos fundamentales comparable en lo esencial a la asegurada por la presente Ley Fundamental. A tal efecto, la Federación podrá transferir derechos de soberanía por una ley que requiere la aprobación del Bundesrat. Los apartados 2 y 3 del artículo 79 se aplican a la creación de la Unión Europea, al igual que a las reformas de los tratados constitutivos y a toda normativa análoga mediante la cual la presente Ley Fundamental sea reformada o completada en su contenido o hagan posible tales reformas o complementaciones.

(1a) El Bundestag y el Bundesrat tienen el derecho de presentar una acción ante el Tribunal de Justicia de la Unión Europea a causa de la infracción de un acto legislativo de la Unión Europea contra el principio de subsidiariedad, El Bundestag está obligado a hacerlo a petición de un cuarto de sus miembros. Por ley, que necesita el acuerdo del Bundesrat, pueden admitirse excepciones del artículo 42, apartado 2, frase 1, y del artículo 52, apartado 3, frase 1, para el ejercicio de los derechos que les son reconocidos al Bundestag y al Bundesrat en los Tratados básicos de la Unión Europea. (2) En los asuntos vinculados con la Unión Europea participan el Bundestag y los Länder a través del Bundesrat. El Gobierno Federal debe informar en detalle y con la menor dilación al Bundestag y al Bundesrat. (3) Antes de participar en los actos normativos de la Unión Europea, el Gobierno Federal dará al Bundestag la oportunidad de expresar su parecer. El Gobierno Federal tendrá en cuenta las tomas de posición del Bundestag en las negociaciones. La regulación se hará por una ley. (4) El Bundesrat debe participar en la formación de la voluntad de la Federación en tanto tuviera que participar en las correspondientes medidas a nivel nacional o en tanto los Länder fueran competentes a nivel nacional. (5) En tanto los intereses de los Länder sean afectados en una materia de competencia exclusiva de la Federación o en la medida en que la Federación tenga, por lo demás, el derecho de legislar, el Gobierno Federal tendrá en cuenta la toma de posición del Bundesrat. Cuando en su esencia sean afectadas las competencias legislativas de los Länder, la organización administrativa o sus procedimientos administrativos, el punto de vista del Bundesrat en eso habrá de ser tenido en cuenta de forma determinante en la formación de la voluntad de la Federación; la responsabilidad de la Federación por el Estado en su conjunto debe ser mantenida. La aprobación del Gobierno Federal será necesaria para toda cuestión susceptible de implicar un aumento de los gastos o una reducción de los ingresos de la Federación. (6) Cuando en su esencia sean afectadas competencias legislativas exclusivas de los Länder en las materias de la educación escolar, de la cultura o de la radiodifusión, el ejercicio de los derechos de que goza la República Federal de Alemania en tanto Estado miembro de la Unión Europea será transferido por la Federación a un representante de los Länder designado por el Bundesrat. El ejercicio de los derechos se realizará con la participación del Gobierno Federal y de acuerdo con él; se mantendrá la responsabilidad de la Federación por el Estado en su conjunto. (7) La regulación de los apartados 4 a 6 se hará por una ley que requiere la aprobación del Bundesrat».

23 En la Constitución italiana la integración en la Unión Europea solo aflora en la distribución territorial del poder para determinar, en lo sustancial (art. 117), que: i) «El poder legislativo será ejercido por el Estado y por las Regiones dentro de los términos de la Constitución, así como de las obligaciones que deriven del ordenamiento comunitario y de los compromisos internacionales» (definiéndose como materia de legislación concurrente la de «las relaciones internacionales y con la Unión Europea de las Regiones»; y ii) «Corres- 
b) Clarificar, simplificándola, la distribución territorial interna del poder constituido, lo que podría hacerse apostando por soluciones ya acreditadas, como, por ejemplo, la alemana, es decir, mediante una doble lista de materias de la competencia: i) exclusiva de las instituciones generales y ii) concurrente de éstas y las entidades políticas territoriales (con el alcance antes expuesto y establecimiento del principio de desplazamiento, en estas últimas materias, del Derecho territorial por el Derecho común o general) y una cláusula residual de competencia a favor de las entidades territoriales. Este esquema de distribución debería ser complementado con una regulación de las relaciones entre las dos instancias territoriales básicas del Estado (régimen de funcionamiento del Estado como un todo, congruente obviamente con el estatuto de su condición de miembro de la Unión Europea) y, en especial, de la participación de las entidades políticas aludidas en los procesos de toma de decisiones en sede de la instancia general (inexcusablemente desde luego en materias de legislación concurrente), para lo cual se ofrecerían dos opciones: la previsión de una Cámara parlamentaria de verdadera representación territorial (que presentaría, sin embargo, el inconveniente de su tendencia a reproducir en la instancia general la dinámica de los partidos políticos, de lógica no necesariamente territorial) y el establecimiento de un órgano de representación de las políticas públicas desarrolladas en sede territorial (por contar con respaldo parlamentario en cada momento), para lo que podría no ser impensable una reconversión del actual Consejo de Estado ${ }^{24}$.

c) Regular asimismo directamente, siquiera en los aspectos esenciales, la organización territorial sobre la base de i) la garantía del autogobierno, conforme a su Estatuto propio y en calidad de entidades políticas, de las diecisiete actuales Comunidades Autónomas (las dos Ciudades Autónomas deberían ser objeto de un tratamiento específico), enunciándolas simplemente por su nombre y el reconocimiento de la singularidad, por razones históricas y de lengua propia, cuando menos del País Vasco y Cataluña, más, en su caso, Galicia; ii) la definición del Estatuto como norma institucional de organización del autogobierno en el marco de la Constitución y de acuerdo con las características propias de la comunidad política institucionalizada; y iii) la diferenciación del autogobierno de

ponde a las Regiones la potestad legislativa en cualquier materia no expresamente reservada a la legislación del Estado. En las materias de su competencia las Regiones y las Provincias autónomas de Trento y Bolzano participarán en las decisiones destinadas a la formación de los actos normativos comunitarios y proveerán a la aplicación y cumplimiento de los acuerdos internacionales y de los actos de la Unión Europea, con observancia de las normas de procedimiento establecidas por una ley del Estado, la cual regulará las formas de ejercicio de la potestad sustitutiva en caso de incumplimiento».

24 Una fórmula en tal sentido ya en L. Parejo Alfonso, «El Gobierno de la Nación y los Gobiernos de las Autonomías territoriales; un problema de articulación», op. cit. en nota 18. 
éstas comunidades políticas de la autonomía en el marco de la Ley de la Administración local, con consiguiente interiorización por aquéllas del régimen de organización y funcionamiento de las entidades locales, sin perjuicio de la garantía constitucional de la autonomía local.

\section{ESTRAMBOTE SOBRE EL INTERÉS GENERAL O PÚBLICO COMO CLAVE PARA LA REVITALIZACIÓN DEL ESTADO.}

Más allá de la actualización del orden constitucional, la realidad española demanda por lo menos con la misma intensidad, como ya se ha adelantado, una verdadera regeneración de la vida política y social y de las instituciones (pero no solo de los partidos políticos, sino también de las propias funciones estatales, sin excluir desde luego el poder judicial, normalmente no objeto — por lo menos con la misma intensidad - de este tipo de reflexiones, pero decisivo para el buen funcionamiento del Estado y la efectividad del orden político y la paz social ${ }^{25}$. Sin perjuicio de la que tiene por si misma, su importancia trasciende al funcionamiento de un Estado complejo como el nuestro, pues de ella depende la vitalidad y autenticidad del pluralismo territorial sin merma de la verdadera, por sustantiva (no formal), unidad constitucional.

Tan es esto así que puede decirse que de poco nos va servir la actualización del texto constitucional si no impulsamos con igual decisión las cuestiones que están fuera de la potencia configuradora del Derecho y que son, sin embargo, condición del buen funcionamiento del Estado. Pues lo que está en juego, cualesquiera que sean las mejoras del diseño del Estado, es nada menos que su capacidad para la definición correcta y la realización eficaz del interés general, es decir, para la recreación continuada de las condiciones de vida conforme a lo requerido por el orden constitucional (el viejo bien común, en definitiva). No por exceder en mucho esta basal cuestión las posibilidades de estas reflexiones deja de ser posible ahora siquiera ilustrar su trascendencia.

Una de las herencias de mayor calado del Estado autocrático preconstitucional, que ha logrado pervivir inercialmente en el constitucional (pervirtiendo su correcto funcionamiento) es la lógica del par de categorías, íntimamente interre-

25 Quizás no se inoportuno realizar aquí un simple apunte sobre la solución a dar al conflictivo órgano constitucional de gobierno del poder judicial. Pues ninguna de las propuestas hasta ahora apuntadas parecen adecuadas para resolver las dificultades que suscita la existencia misma de tal órgano en los términos establecidos por el artículo 122 CE e ínsitas en el hecho de la atribución de funciones de gobierno (por más que sea de lo propio) a un poder de las características peculiares del judicial, atenido a la función señalada en el artículo $117 \mathrm{CE}$. En caso de no estimarse oportuno el regreso a su sede tradicional de la «administración» de los asuntos relativos a la dotación de medios al poder judicial, ¿por qué no pensar en la creación de una Autoridad Independiente para el cumplimiento de tal cometido? ¿O es que la referida administración es menos trascendente y menos precisada de preservación de la interferencia de «la política» que los sectores económicos autorregulados bajo el control de una autoridad de tal tipo? 
lacionadas, «asuntos públicos» e «interés general o público», entendido el primero como el ámbito de lo que concierne a todos y debe ser y es objeto de debate continuo $^{26}$; y el segundo como la fórmula jurídica expresiva de forma abstracta y condensada de los fines a alcanzar en cada caso por el Estado y que apela a un proceso de concreción para su definición en cada supuesto por el órgano estatal competente ${ }^{27}$. Sus características coinciden esencialmente con las identificadas por P. Häberle ${ }^{28}$ en la que ha supuesto la tradición monárquica alemana para la que califica de res publica constitucional: i) absorción de todo lo público por el Estado (si se prefiere: estatalidad de todo espacio público y del interés general) y conversión del Estado en fuente única de definición de dicho interés (determinación voluntarista del interés general desde y por el poder público); ii) la reducción del juego del interés general al ámbito propio de la Administración pública y su modo específico de toma de decisiones (sinécdoque del Estado), haciendo equívoca su posición en el del juego de las restantes funciones-poderes del Estado (el legislativo y el judicial); iii) la contraposición de lo público y lo privado (desde la suposición de la superioridad general del interés público respecto del privado), con reserva al interés general del papel de título de intervención en la libertad y propiedad y — como correlato - el descuido del carácter «público» de la libertad; y, en definitiva, iv) la interpretación del interés general o público como magnitud extrajurídica (incluso extraconstitucional) determinante, de un lado, de una falsa alternativa entre lo no jurídico (el bien común perteneciente a la dimensión subjetiva del decisionismo estatal) y lo jurídico, el Derecho (perteneciente a la dimensión objetiva de la convivencia social) y, de otro lado, de una concepción del Derecho público (en particular administrativo) como Derecho de las relaciones de sujeción colocado bajo la reserva del juego de incisivos intereses públicos.

Si puede así entenderse la reticencia y el escepticismo doctrinales respecto de la categoría del interés público (el clásico bien común) ${ }^{29}$, no cabe compartirlo por

26 La categoría está presente en nuestro texto constitucional. El artículo 76.1 habilita a cualquiera de las Cámaras parlamentarias y, en su caso, a ambas conjuntamente para nombrar Comisiones de investigación sobre «cualquier asunto de interés público», cuyas conclusiones no son vinculantes para los Tribunales, es decir, para analizar cuestiones que conciernen a la ciudadanía y en modo alguno para alcanzar una definición del interés general o público, como prueba el hecho de las conclusiones del análisis no vinculan a los Tribunales, que son los llamados a tener la última palabra en la determinación en cada caso concreto del interés general. Y el artículo 124.1 incluye en la misión de promoción de la justicia propia del Ministerio Fiscal la defensa del interés público tutelado por la Ley y la procura del interés social.

27 Esta categoría aparece nítidamente en los artículos 30, 44 y 47 de la Constitución, que aluden, respectivamente al «cumplimiento de fines de interés general» como objetivo del establecimiento de un posible servicio civil y criterio tanto de la acción de los poderes públicos de promoción de la ciencia y la investigación científica y técnica, como de la regulación de la utilización del suelo.

28 P. Ḧ̈BERLE, Öffentliches Interesse als juristisches Problem, Berliner Wissenschaftsverlag, 2.a ed. (la 1. es de 1970), Berlín 2006.

29 Por todos, A. Nieto, La «Administración sirve con objetividad los intereses generales», en Estudios sobre la Constitución Española, libro homenaje al profesor Eduardo García de Enterría, T. III, Civitas 1991. 
ser hoy la categoría tanto o más necesaria que nunca. Si, como bien apunta P. Häberle, en la res publica actual la Constitución debe entenderse como orden normativo del bien común y, por tanto, proceso público de determinación de éste, ineludible es la refundación de su trasunto jurídico: el interés general o público — precisamente como categoría jurídica y no exclusivamente filosófica, política o sociológica - según la lógica propia del Estado democrático y social de Derecho de estructura territorial plural, integrado en estructuras supranacionales e inmerso en la vida internacional. Pues en el orden a cuyo servicio está dicho Estado no existe ya fundamento alguno para concebirlo como simple manifestación de la voluntad del soberano, del poder público estatal; poder público que hoy no monopoliza lo público.

La necesidad de la apuntada refundación se hace inmediatamente presente si se considera el papel que desempeña el Juez (constitucional y ordinario; europeo e interno) en tal Estado y que no es otro que la determinación última, en términos de law in action, de lo que sea o no sea, jurídicamente hablando y en cada caso, el interés general. Y requiere la completa renovación, vistos en su interacción, de los conceptos «asuntos públicos» e «interés general», sobre la base de la recuperación de su servicio a los valores y bienes fundamentales del referido Estado.

En la Constitución, en efecto:

a) Ni el interés general o público está inscrito sin más en el Estado, ni éste agota los «asuntos públicos». Esto último resulta sin más del derecho fundamental de los ciudadanos de participar —individualmente o agrupados de diversas formas - cabalmente en «los asuntos públicos» (art. 23.1 CE) y el correlativo deber de todos los poderes públicos de facilitar dicha participación en la vida política, económica, cultural y social (art. 9.2, in fine, CE), obviamente desde la defensa de los diversos intereses que se decantan en dicha vida (a los que aluden los artículos 7, 28.2 y 52 -intereses económicos, sociales y profesionales propios de los sindicatos de trabajadores, las asociaciones empresariales y las organizaciones profesionales; 24,1 — los intereses legítimos de todas las personas-; y 51 los intereses legítimos de los consumidores y usuarios-; todos ellos de la CE). Pero de ello se desprende igualmente la íntima relación del proceso de debate de los asuntos públicos así precisado con la definición del interés general o público: ésta no es separable de aquél.

Por más que el concepto de interés general o público se emplee por el constituyente con significados y alcances diversos, es claro en todo caso que no es monopolizado por el Estado. Así se desprende del hecho de que la acción de los particulares pueda procurarlo bajo la protección y, en su caso, el fomento del Estado (arts. 34.1 CE relativo al derecho de fundación; 44.2 CE atinente a la actividad de investigación científica y técnica; pero, especialmente, 33.3, en la medida en que el interés social puede constituir —en paridad funcional con la utilidad pública - causa legítima de la expropia- 
ción forzosa), pero sobre todo de la subordinación de toda la riqueza del país en sus distintas formas (actividades y bienes) y sea cual fuere su titularidad (públicos, como privados) y desde luego del dato ya concluyente de que el orden constitucional mismo de derechos fundamentales y libertades públicas presidido por el valor de la dignidad de la persona y el libre desarrollo de la personalidad en sociedad sea de interés general.

En palabras de P. Häberle: aunque el interés general o público no ha emigrado del Estado, lo ha desbordado penetrando ámbitos tradicionalmente asignados a la sociedad, de modo que su percepción y realización acaecen igualmente en el campo propio de la libertad. Lo confirma la actual asunción por el Estado, respecto de tareas esenciales en sectores económicos de relevancia, de la posición de garante de la dación de bienes y la prestación de los servicios correspondientes con entrega del cumplimiento de las aludidas tareas al mercado y, por tanto, a la acción de los actores que operan en ellos con la lógica propia del mismo.

De esta suerte, no por primar, en el caso, el interés general o público (una vez definido) sobre el interés particular, aquél tiene sin más y con carácter general una posición superior respecto del interés privado. La regla de la subordinación de uno a otro proclamada en el artículo 128 CE debe entenderse en el caso (cual luce en la hipótesis de contraposición irreductible que legítima la expropiación forzosa en el artículo 33.3 CE). Esta solo aparente paradoja se explica perfectamente considerando que la Constitución funda no tanto un status libertatis (en el sentido de G. Jellinek) cuanto una relación jurídico-constitucional. Pues la perspectiva que ésta abre permite — como sostiene R. Gröschner ${ }^{30}$ — superar la idea de la superioridad del Estado (con correlativa subordinación a él del individuo) y, con ella, la concepción organicista de aquél. Pues:

- Carece de las implicaciones de la doctrina del status y, concretamente, la de la integración de las partes en el complejo orgánico del Estado, careciendo, por ello, del condicionamiento del status subiectionis constitutivo, según aquella doctrina, del fundamento mismo del Estado y de la consecuente exclusión de verdaderas relaciones jurídicas entre los individuos y el Estado.

- En la relación jurídica (que no postula, pues, integración alguna orgánica en el Estado) una cosa es que todas las partes en ella deban tener plena capacidad y otra distinta la distribución en su seno de los derechos y las obligaciones y, como consecuencia de ella, la superioridad de unas partes sobre otras. Y la jurídico-constitucional implica de

30 R. Gröschner, Das Überwachungsrechtsverbältnis, J.C.B. Mohr (Paul Siebeck), Tübingen 1992, pp. 67 y sgs. 
suyo la vinculación del legislador por los derechos fundamentales, toda vez que éstos impiden, por su propia naturaleza, que la posición jurídico-material contrapuesta del Estado sea superior a la que ellos proporcionan. La posición del titular de un derecho fundamental frente al legislador no es, por ello, la de sujeción o subordinación en el sentido clásico, sino cabalmente una de principal igualdad. Para lo que es capital que las potestades estatales asimismo fundamentales o básicas se conciban como poderes jurídicos equivalentes a los derechos fundamentales (sobre la base del principio constitucional de igualdad material).

Pues bien, en la relación jurídico-constitucional los poderes-funciones básicos estatales, aún teniendo un titular determinado, carecen aún de destinatario(s) concreto. La potestad de legislar lo es, en efecto, respecto a todos los titulares de derechos fundamentales, de modo que solo ulteriormente experimenta determinación y encuentra límites a propósito de i) un preciso proceso normativo y ii) en caso de conflicto con, es decir, afectación de concretos derechos fundamentales. Esta diferenciación de dos momentos sucesivos en la potestad legislativa (existencia en la norma constitucional y determinación ulterior con ocasión del ejercicio) se corresponde justamente con la distinción entre las relaciones jurídicas calificadas como generales y las conceptuadas como especiales. Pues solo en estas últimas surge la reciprocidad de posiciones activas y pasivas concretas que son totalmente prescindibles en la general constitucional, dado que en ella solo se trata de establecer las posiciones (potestades) fundamentales o básicas de los poderes públicos constituidos en el contexto de la relación generada por el propio orden constitucional; potestades que expresan ciertamente la idea unitaria basal de un poder público regulador capaz de imponerse, es decir, del fenómeno de establecimiento y ejecución unilaterales del Derecho, que se expresa en nuestro ordenamiento jurídico de manera fuerte en el artículo 9.2 CE.

El Estado está, pues, habilitado para establecer unilateralmente regulaciones jurídicas, es decir, dictar Leyes, producir actos y adoptar fallos y, con ello, generar la validez y la vigencia jurídicas (de una Ley o un Reglamento, de un acto o de una sentencia) solo pensables justamente en virtud de la autoridad estatal. Refiriendo esta habilitación y, por tanto, la correspondiente potestad a relaciones de la vida social aparecen de suyo las tres formas correlativas en que la regulación de tales relaciones puede tener lugar: como regulación general por Ley o Reglamento en el contexto de la relación jurídico-constitucional, como regulación especial por acto, convenio o contrato administrativos en el contexto de la relación jurídico-administrativa y como regulación especial inter partes por sentencia en el contexto de la relación jurídico-procesal. 
b) La diversidad de intereses que, como acaba de verse, es propia del ámbito social y se transmite al político en congruencia con el principio de Estado democrático y el valor superior del pluralismo político (art. $1 \mathrm{CE}$ ), se da igualmente en el seno mismo del Estado y por razón de su organización territorial. Como tempranamente puso de relieve S. Muñoz Machado ${ }^{31}$, el actual artículo $137 \mathrm{CE}$ vincula las instancias territoriales, en efecto, con «círculos de interés», construyéndolas, así, por relación a la gestión de «sus respectivos intereses». Lo que implica implícitamente la existencia de un círculo de intereses de la instancia territorial general. Por ello, el texto constitucional diferencia a lo largo de su articulado, además del interés de España (como el todo) a la hora de la decisión sobre la sucesión en la Corona (art. 57.3 CE), los intereses generales (entendidos como los gestionados por la instancia territorial asimismo general), cual sucede a propósito tanto de la distribución territorial de competencias (art. 149.1, $20 .^{\mathrm{a}}$ y $24 .^{\mathrm{a}}$ : puertos, aeropuertos y obras públicas de interés general), como del empleo del mecanismo propio de la llamada coacción federal (art. 155: caso de atentado grave al interés general de España).

c) La estructura territorial del Estado comporta, pues, la coexistencia de percepciones diversas (subjetivas por imputables a cada una de las organizaciones de aquella estructura) del interés general en doble el sentido de público y objetivo. Como quiera que, de acuerdo en último término con la Constitución, en cada asunto solo puede haber un interés general o público objetivo (el que corresponda con el bien común que deba entenderse querido por el orden fundamental), su determinación solo puede ser resultado de procedimientos decisionales en que hayan podido hacerse valer y efectivamente hayan sido adecuadamente ponderados todos los intereses (de sujetos privados —individuales y grupales - y de sujetos públicos) reveladores de concernencia por el objeto de tales procedimientos. Lo que, en el plano que ahora interesa, significa el ejercicio por cada instancia territorial de sus propias competencias en términos acordes con la lealtad institucional, es decir, con los principios de colaboración, cooperación y coordinación (principios que representan, así, tanto un criterio, como un límite en el ejercicio de las referidas competencias). Dicho de otra manera: la observancia de tales principios es condición de la jurídicamente correcta definición, en el orden constitucional, del interés general o público.

Esta definición, por último, no es, en el Estado constitucional, incumbencia exclusiva de la función ejecutiva y, menos aún, dentro de ella, de la Administración pública. Como ha señalado certeramente P. Häberle, 
en dicho Estado la Administración pública ha perdido el monopolio del interés público en el sentido de la relación escasa o lejana con el del legislador y el poder judicial.

La correcta lectura del artículo 103.1 CE así lo revela: si la Administración es servicial del interés general con sometimiento pleno a la Ley y el Derecho es porque aquél ha sido prefigurado bien por el legislador (y, en todo caso, por la Constitución). Reservas a este respecto al legislador no faltan en el texto fundamental: el articulo 30 por lo que hace al establecimiento de un servicio civil alternativo al militar; el artículo 128.2 CE en cuanto respecta a la reserva al sector público de recursos o servicios esenciales y a la intervención de empresas; y artículo 150 para la fijación de los principios de armonización de las disposiciones normativas de las Comunidades Autónomas.

d) La atribución en exclusiva a los Jueces y Tribunales de la función de juzgar y ejecutar lo juzgado y la obligación constitucional de cumplir las resoluciones judiciales (arts. 117 y $118 \mathrm{CE}$ ) —así como también la reserva al Tribunal Constitucional de la declaración de inconstitucionalidad de las Leyes (art. $161 \mathrm{CE}$ ) — implican la reserva al poder judicial y, en su caso, al Tribunal Constitucional (dando por sobreentendida la inclusión asimismo, y en lo pertinente, del Tribunal de Justicia de la Unión Europea) de la definición última y definitiva, en cada caso, de lo que sea el interés general o público (en su caso confirmando la efectuada por el correspondiente poder público). Lo que da cuenta de la decisiva trascendencia de la función jurisdiccional para la determinación jurídica del interés general o público.

Basten las consideraciones anteriores para justificar la afirmación de la necesidad de la refundación y revalorización del interés general o público (como categoría jurídica) como presupuesto de la regeneración de la vida política y social y el buen funcionamiento de las instituciones y el Estado en su papel de procura del bien común en la realización efectiva y continuamente renovada del orden constitucional. A cuyo efecto en modo alguno son ociosas las siguientes observaciones de P. Häberle (desde el recuerdo de la máxima máxima fiat salus publica ne pereat res publica y la sentencia ciceroniana est autem res publica res populi):

1. La cláusula del interés general o público no es ciertamente una receta susceptible de ser concretada por el método de la simple subsunción, pero ello no le impide permitir el desarrollo del proceso de concreción en términos jurídicos y sobre la base de la trascendencia, según su formulación en cada caso, de los planos bien sustantivo (valores y bienes jurídicos implicados), bien sobre todo procedimental (observancia del due process).

2. El interés general o público, por tanto, no es susceptible de definición, ni es determinable desde sí mismo, siendo solo susceptible de ser concretado 
(cuando no venga ya precisado por el legislador) en el contexto de las circunstancias sustantivas, funcionales, competenciales y procedimentales del caso.

TITLE: Territorial pluralism and Constitution

AвSTRACT: The basque and catalan conflict — the second nowadays at his peak- demand a revamp of Spain's constitutional order to adapt the organization of the state to the diverse structure of the country. Such reform should be addressed taking into account the radical transformations resulting from its integration into the European Union project and from an increasingly interdependent comunity at the international level. This article points out the most important aspects of the reform or (where relevant) of the constitutional review that the author considers more feasible. This appraisal will be carried out based on the analysis of the current situation and looking to the future, as well as on the experience gained with the political transition, the constitutional consensus and the so called Authonomic State-making process. However, the sucess of this commitment within the constitutional and legal framework depends on something that is out of the shaping capacity of the law - the political and social life renewal, as well as of the institutions - and has a crucial importance for the functioning of a complex state such as the spanish and, therefore, for the vitality and authenticity of the territorial pluralism without affecting (in a substantive — not formal — way) the constitutional unity.

RESUMEN: Las llamadas cuestiones vasca y catalana (boy, la segunda, en fase aguda) reclaman una actualización del orden constitucional en punto a la adecuación de la organización del Estado a la estructura plural de España, que ha de hacerse teniendo en cuenta las radicales transformaciones derivadas de la integración en la Unión Europea y la inserción en una comunidad internacional cada día más interdependiente y desde una doble reflexión. En el trabajo se apuntan —en sus líneas maestras — los aspectos más sobresalientes de la reforma o, en su caso, revisión constitucional que el autor considera más viable sobre la base del análisis tanto de la situación presente y mirando al futuro, como de la experiencia suministrada por la transición política, el consenso constitucional y el proceso de construcción del llamado Estado autonómico. Pero recordando que el éxito de tal empeño en el plano jurídico-constitucional depende de algo que está fuera de la potencia configuradora del Derecho — la regeneración de la vida política y social y de las instituciones y tiene una decisiva trascendencia para el funcionamiento de un Estado complejo como el español y, por tanto, la vitalidad $y$ autenticidad del pluralismo territorial sin merma de la verdadera, por sustantiva (no formal), unidad constitucional.

KEY wORDS: Territorial pluralism, Constitution.

Palabras Clave: Pluralismo territorial, Constitución.

FECHA DE RECEPCIÓN: 07.12.2015 FECHA DE ACEPTACIÓN: 15.01.2016 